\title{
Immunologic Responses against SARS-CoV-2
}

Cássio Santana Meira ${ }^{1,2}$, Vinícius Pinto Costa Rocha ${ }^{1,2}$, Iasmim Diniz Orge ${ }^{1}$, Danielle Devequi Gomes Nunes ${ }^{1}$, Emanuelle de Souza Santos ${ }^{1,2}$, Gabriela Louise de Almeida Sampaio ${ }^{1,2}$, Patrícia Kauanna Fonseca Damasceno ${ }^{1,2}$, Afrânio Ferreira

Evangelista $^{1}$, Luciana Knop ${ }^{1}$, Ricardo Ribeiro dos Santos ${ }^{1,2}$, Roberto Badarón, Milena Botelho Pereira Soares ${ }^{1,2^{*}}$ ${ }^{1}$ SENAI Institute of Innovation in Advanced Health Systems, SENAI CIMATEC; ${ }^{2}$ Gonçalo Moniz Institute, Oswaldo Cruz Foundation (FIOCRUZ); Salvador, Brazil, Brazil

Coronavirus disease 2019 (COVID-19) emerged in Wuhan, China, in December 2019 and quickly spread worldwide becoming a global health problem unprecedented. The infection is caused by severe acute respiratory syndrome coronavirus 2 (SARS-CoV-2) that is characterized as a RNA virus with an envelope derived from host cell with glycoprotein spikes, appearing like a crown-like external structure under electron microscope. Due to the aggressive spread profile of SARS-CoV-2, the scientific community is under pressure to generate knowledge about the morphology of the virus and the immune response against SARS-CoV-2, in order to generate useful information for the development of vaccines and methods of immunological diagnosis. Previous knowledge about other coronaviruses, such as SARS-CoV-1 and MERS-CoV, were the pillars for understanding the immune response of SARS-CoV-2. Until now, we know that the anti-SARSCoV-2 immune response in the host involves mechanisms related to innate immunity, activation of CD4+ and $\mathrm{CD8}+\mathrm{T}$ cells and production of antibodies (IgA, IgG and IgM) against the virus. In spite of being a new pathogen, the literature on SARS-CoV-2 has increased dramatically in the past few months, especially in the immunology field. Here, we review the literature on SARS-CoV-2 immunology, focusing on the innate and adaptative immune responses.

Keywords: COVID-19. SARS-CoV-2. Immunologic Response. Immunity.

\section{Introduction}

Coronavirus disease 2019 (COVID-19) emerged in Wuhan, China, in December 2019 and quickly spread to other cities and countries, being currently classified as a pandemic by the World Health Organization (WHO) [1,2]. The infection is caused by severe acute respiratory syndrome coronavirus 2 (SARS-CoV-2), which became well-known for its high transmissibility and pathogenicity [3]. According to the WHO, SARS-CoV-2 has infected more than 48 million people worldwide, with more than 1 million confirmed deaths, being the United States, India and Brazil the countries most affected [4]. Despite all the efforts to control the virus spread, daily new

Received on 2 March 2020; revised 9 June 2020.

Address for correspondence: Dra. Milena Soares. ISI-SENAI CIMATEC. Av. Orlando Gomes, 1845, Piatã. Zip Code: 41650-010. Salvador, Bahia, Brazil. E-mail:milena.soares@ fieb.org.br.

J Bioeng. Tech. Appl. Health

(D)2020 by SENAI CIMATEC. cases and deaths related to SARS-CoV-2 are being reported worldwide.

SARS-CoV-2 is not the first coronavirus that cause human global outbreaks. In 2003 and 2012, SARS (retrospectively named SARS-CoV-1) and Middle Eastern respiratory syndrome (MERS) CoVs, respectively caused outbreaks in several countries $[5,6]$. Despite the genetic similarity between the three virus, SARS-CoV-1 and MERS$\mathrm{CoV}$ exhibited only limited person-to-person spread, resulting in dramatically lower numbers of confirmed cases when compared to SARS-CoV-2 [7]. Due to the aggressive spread profile of SARSCoV-2, an unprecedented economic and health crisis was caused worldwide. In this context, an urgent need arose regarding knowledge about the immunology of SARS-CoV-2, in order to generate useful information for the development of vaccines and methods of immunological diagnosis.

In spite of being a new pathogen, the literature on SARS-CoV-2 has increased dramatically in the past few months, especially in the immunology field. Here, we review the literature on SARSCoV-2 immunology, focusing on the innate and adaptative immune responses. 


\section{Structural Basis of SARS-CoV-2}

Coronaviruses belong to Coronaviridae family of order Nidovirales and are classified into four genera that include $\alpha-, \beta-, \gamma-$, and $\delta$ coronaviruses. They have a viral envelope derived from host cell with glycoprotein spikes, appearing like a crownlike external structure under electron microscope [8].

Coronaviruses have the largest RNA genomes (27 to $32 \mathrm{~kb}$ ) among the RNA viruses. Their positive-sense single-stranded RNA genome is involved in a nucleocapsid of helical symmetry when relaxed and spherical when inside the virus. They use a nested set of mRNAs produced by the viral RNA polymerase for replication in the cytoplasm of the host cell $[9,10]$.

There are three types of coronaviruses that evolved to cause severe pulmonary diseases in humans since the beginning of this century which are the SARS-CoV-1, MERS-CoV and the new emerged SARS-CoV-2 [11]. The genome of SARS-CoV-2 shares about $82 \%$ sequence identity with SARS-CoV-1 and MERS-CoV and encodes four major structural proteins: spike (S) glycoprotein, small envelope (E) glycoprotein, membrane (M) glycoprotein and nucleocapsid $(\mathrm{N})$ protein. In addition, there are several accessory and non-structural proteins (nsp1-16) produced during SARS-CoV-2 infection [12].

The transmembrane homotrimer $\mathrm{S}$ protein forms the spike structure in the viral surface that plays an essential role in viral attachment, fusion, entry and transmission in host cells. This protein is cleaved by host cell furin-like protease into two subunits (S1 and S2). The presence of this furin-like cleavage site in SARS-CoV-2 facilitates the $\mathrm{S}$ protein priming what might explain the transmission efficiency improvement of SARS$\mathrm{CoV}-2$ when compared to other beta coronaviruses [13].

The S1 subunit is responsible for the receptor recognition process and can be divided into a $\mathrm{N}$-terminal domain (NTD) and a C-terminal domain (CTD), that is also called receptor binding domain (RBD), and the S2 subunit, on the other hand, is correlated with virus membrane fusion process. The SARS-CoV-2 enters in host cell by the attachment of the $\mathrm{S}$ glycoprotein to the angiotensin-converting enzyme 2 (ACE2) receptor, expressed in lower respiratory tract cells and also in various organs such as heart, lungs, kidneys and gastrointestinal tract $[10,14]$ (Figure $1)$.

Other important SARS-CoV-2 structural component is the $\mathrm{N}$ protein that forms the nucleocapsid. This protein is highly phosphorylated, increasing its affinity to the viral RNA. The $\mathrm{N}$ protein is involved in processes related to the viral genome, the viral replication cycle and the cellular response of host cells to viral infections [15].

Moreover, the M protein, found in high amount at the virion structure as a transmembrane dimer, plays a role in the maintenance of membrane conformation and shape. On the other hand, the scarcely found $\mathrm{E}$ protein, also a transmembrane protein, may help in the virus assembly and release and has an ion channel activity that could be important to the viral pathogenesis [10].

\section{Innate Immunity against SARS-CoV-2}

The innate immunity is the first line of defense against invasive microorganisms. The response of innate immunity is not specific to a particular pathogen, but it can recognize conserved patterns among them and quickly respond to an invasion process. The innate immune response is also responsible to activate the adaptive immune system, which is a more specific response which can also keep memory and avoid a re-infection [16].

Regarding SARS-CoV-2 infection, it was described that the initial response in innate immunity is triggered by the engagement of pattern recognition receptors (PRRs) by viral genomic material by cytosolic RIG-I like receptors (RLRs) and extracellular and endosomal Toll-like receptors (TLRs), specially TLR-3, this activation starts the 
Figure 1. Schematic representation of the SARS-CoV-2 structure and its mode of host entry.

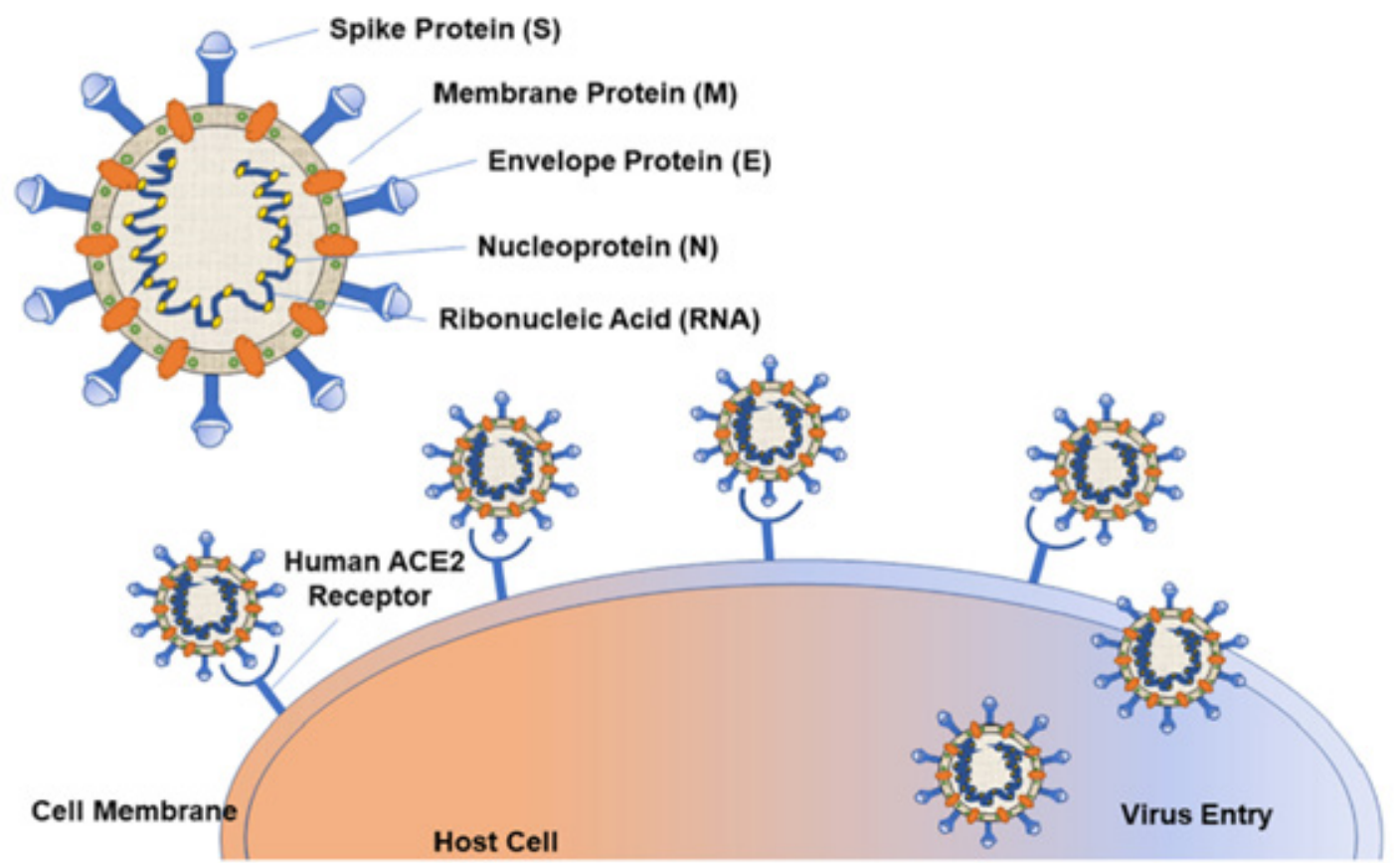

Credit/Source: Naqvi and colleagues [15a].

signaling cascade to produce type I/III interferons, tumor necrosis factor-alpha (TNF- $\alpha)$, interleukin-1 (IL-1), IL-6 and IL-18 (Figure 2). Together, these cytokines induce antiviral programs in immune cells and potentiate the adaptive immune response [17]. Recent studies indicate that a critical role of innate immunity to SARS-CoV-2 includes the action of Type I Interferon (IFN-I) response [18].

Type I IFNs are polypeptides secreted by infected cells after activation of pattern-recognition receptors, and play an important role in signaling the body to infection in course. Their function includes: activation of intracellular antimicrobial responses, turning the cells refractory to the infection, limiting the virus spread, modulation of cellular innate immune response, promoting antigen presentation, activation of Natural Killer cells $(\mathrm{NK})$, and modulation of pro-inflammatory pathways contributing to the activation of adaptive immune system [20]. Among IFN-I molecules, IFN- $\alpha$ and IFN- $\beta$ have an important antiviral action in SARS-CoV-2 infection. They are produced by macrophages in the first few hours of the infection and peak at the first 8 to 10 days of symptom onset, inducing the transcription of IFN-stimulated genes and displaying a strong pro-inflammatory response [21].

Analysis of bronchoalveolar lavage fluid cells (BALF) have shown that SARS-CoV-2 viruses can efficiently suppress Type I IFN induction and antagonize its effects. It was observed that when exposed to SARS-CoV-2 infection, the cells failed to induce competent IFN-I responses, favoring the escape of the virus to the immune sensing and delaying the adaptive immune response [18]. Moreover, it was described for other types of SARS-CoV that the failure to elicit an early Type I IFN response correlates with the severity of disease, which has also been observed in COVID-19 [22].

The myeloid cells of innate immunity also play an important role in COVID-19. Activated HLADRhiCD11chiCD14+ monocytes were found increased in patients with mild symptoms, while 
Figure 2. Immune response against SARS-CoV-2.

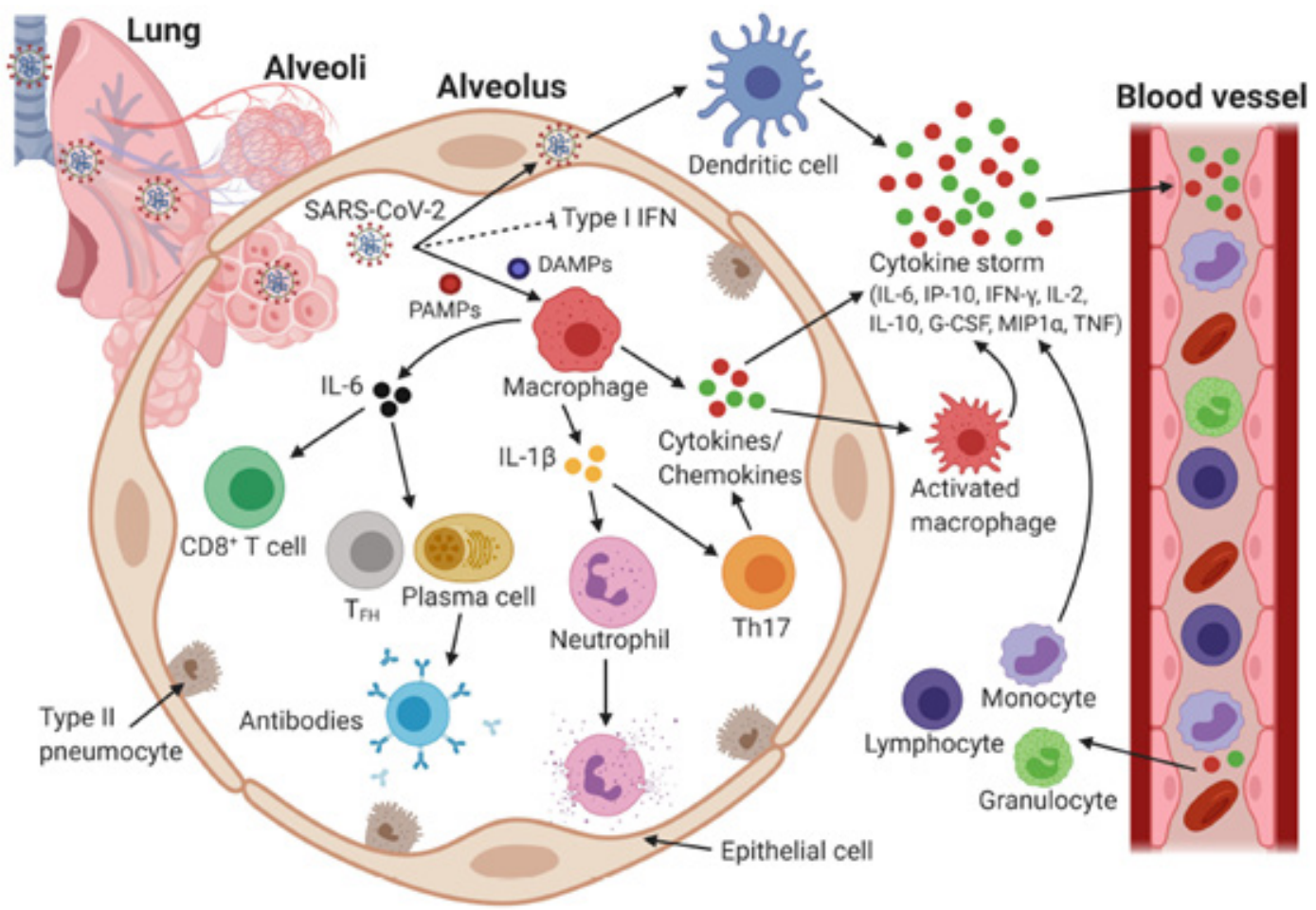

The initial response against SARS-CoV-2 is triggered by activation of viral pathogen-associated molecular patterns (PAMPs) and dangerassociated molecular patterns (DAMPs) which culminates with the release of proinflammatory molecules by endothelial cells, epithelial cells and tissue-resident macrophages, such as G-CSF, IFN- $\gamma$, IL-2, IL-6, IL-10, M1P $\alpha$ and TNF. Macrophages and virus-infected dendritic cells activated by cytokines/chemokines increase the production of additional cytokine and chemokines, which is known as cytokine storm. The immune response also counts with recruitment of neutrophil, T-helper type 17 cells, CD8+ T cells and B cells.

Credit/Source: Frederiksen and colleagues [19].

monocytes characterized by low expression of HLA-DR and anti-inflammatory markers genes (CD163 and PLAC8) appeared in patients with severe COVID-19 [23].

Moreover, it was described that cells infected by SARS-CoV-2 viruses overexpressed six chemokines that belong to the human ontology "Neutrophil Chemotaxis" including CXCL1, CXCL2, CXCL3, CXCL5, IL-8 (CXCL8), and CCL20 [24]. These chemokines attract neutrophils to the lungs. In COVID-19, neutrophil recruitment and activation, and the presence of neutrophilderived extracellular traps that cause damage to the tissue observed in hospitalized patients are markers previously reported in hyperinflammatory conditions [24, 25].

Innate lymphoid cells are also involved in the innate imune response, they work as effector cells divided into cytotoxic and non-cytotoxic groups. In the cytotoxic side the NKs are reported to act as early antiviral response. Interestingly, it was observed a reduction of resident NKs in the lung of moderate to severe COVID affected patients, while only in the severe cases new adaptive NKs have been attracted to the inflammation site and contributed to the hyper-inflammation that aggravate the symptoms. Therefore the recruitment of new adaptive NKs has been linked as a marker of a worse prognosis [26, 27].

An interesting link that can be useful to understand the role of innate immunity plays in COVID-19 regards the fact that children account for less than $5 \%$ of diagnosed cases, and from those approximately $90 \%$ are diagnosed as asymptomatic, mild or moderate for the disease [28]. As children have been less exposed to less 
infections during the course of their lifetime and have not developed yet most of its adaptive immune responses, there is a strong suggestion that their more active innate immune response plays a crucial role in responding to SARS-CoV-2 infection [29, 30]. It is hypothesized that children can respond better to the cytokine storm through modulation of the levels of myeloperoxidase, IL-6, IL-10 and p-selectin, avoiding the hyper-inflammation that leads to the severity of acute respiratory distress syndrome observed in the adults [31]. Moreover, aging impairs the fully function of the cells from the immune system, decreasing TLR functions in monocytes, macrophages and dendritic cells; increasing basal cytokine production by dendritic cells; reducing cell signaling, chemotaxis; and triggering inflammatory dysregulations and persistent inflammation, potentiating and ageassociated inflammatory environment leading to the complications in COVID-19 observed for the elderly patients [32].

Altogether, the studies suggest that the key to decrease disease fatality is to induce the stimulation of this first immune response that make the bridge between the innate and adaptive immunity, even though the balance and timeframe of this induction is very sensitive, since the presence of those components early in disease can be protective but if prolonged can hyperactivate the inflammatory response and become pathogenic [33].

\section{T-Cell Immunity to SARS-CoV-2}

The transition between innate and adaptive immune responses is essential for the clinical progression or control of SARS-CoV-2 infection. The antiviral response in the host involves mechanisms related to innate immunity, activation of $\mathrm{CD} 4+$ and $\mathrm{CD} 8+\mathrm{T}$ cells and production of neutralizing antibodies against the virus [34]. In this sense, $\mathrm{CD} 4+$ and $\mathrm{CD} 8+\mathrm{T}$ cells play a role in balancing the fight against pathogens and the risk of developing autoimmunity or hyperinflammation [35]. During the immune response to viruses, $\mathrm{CD} 4+\mathrm{T}$ cells are responsible for inducing $\mathrm{B}$ lymphocytes to produce specific antibodies against the virus, while $\mathrm{CD} 8+\mathrm{T}$ cells have the ability to destroy infected cells [36].

Severe lymphopenia is associated with the poor prognosis of COVID-19 [37, 38]. Recently, a study demonstrated that patients with the severe form of COVID-19, showed T-cell lymphopenia, associated with a decrease of regulatory $\mathrm{T}$ cells and increase of ratio of naive CD4+ cells in relation to memory CD4+ cells [38]. In addition, about $80 \%$ of the total inflammatory cells found in the lung tissue of patients infected with SARSCoV-2 are CD8+ T cells type $[39,40]$. In this context, a deficient immune response to prevent the replication of the virus and the elimination of infected cells, associated with the decrease in $\mathrm{CD} 4+\mathrm{T}$ cells and its subset of regulatory $\mathrm{T}$ cells, contribute to reduction of neutralizing antibodies production and can activate a range of immune system cells, resulting in increase of production of pro-inflammatory cytokines, known as cytokine storm. This phenomenon can cause lymphocyte apoptosis and it is responsible for triggering severe acute respiratory syndrome as well as systemic disorders, such as disseminated instravascular coagulation observed in patients with the severe form of COVID-19 [40-42].

Although antibody production were undetectable, virus-specific memory $\mathrm{T}$ cells have been found in individuals 6 years after the recovering of SARS-CoV infection [43]. In 2016, $\mathrm{Ng}$ and colleagues [44] demonstrated that memory $\mathrm{CD} 8+\mathrm{T}$ cells shown specific reactivity for regions of the membrane proteins and nucleocapsid of the SARS-CoV. In addition to this fact, recently it was observed that SARS$\mathrm{CoV}-2$ has a protein structure genetically similar to SARS-CoV-1 [45]. This observation, can suggest that conserved regions of the epitopes can trigger an immune response against various coronaviruses, serving as an important strategy for the development of vaccines and prevent the possibility of re-infection caused by mutant strains of the virus [46]. 


\section{Humoral Immunity against SARS-CoV-2}

The humoral immune response, especially the production of antibodies, plays an important role in protecting and limiting infections at later phase, and prevent future re-infection. Although SARS-CoV-2 is a novel pathogen, a robust B cell response against the virus is well characterized with the detection of virus-specific IgA, IgG, IgM and neutralizing $\operatorname{IgG}$ antibodies during the course of infection and after virus clearance [17]. The SARS-CoV-2 internal $\mathrm{N}$ protein and the external $\mathrm{S}$ glycoprotein are the sites of antibodies biding. Interestingly, the receptor binding domain (RBD) of Spike protein appears as target of neutralization antibodies and also shows non crossreactivity to RBD from MERS-CoV or SARS-CoV-1, being a promise tool in the diagnostic and immunization fields [47].

In order to understand the dynamic of antibody response against SARS-CoV-2, the response triggered by SARS-CoV-2 are speculated to be similar with the immune response caused by SARS-CoV- 1 once they share $82 \%$ of sequence identity [48]. The antibody profile against SARS$\mathrm{CoV}-1$ virus has a typical pattern of $\operatorname{IgM}$ and $\operatorname{IgG}$ production [49]. Triggering a humoral S- and $\mathrm{N}$-specific IgM response where IgM peak happens within 4 weeks and becomes undetectable 3 months post symptoms onset (PSO); and the switch to IgG occurred around day 14 , and can last for a time [50-52].

In the course of SARS-CoV-2 infection, an increase in virus-specific IgM and IgA during the acute phase of the disease followed by an increase in virus-specific $\mathrm{IgG}$ at later phases has been observed $[53,54]$. However, given the short time since the beginning of the COVID-19 pandemic, it is not well elucidated this sequence of seroconversion, as well as for how long the protecting levels of these blocking antibodies will remain active and protective [55].

The typical view on IgM responses preceding IgG responses were observed by some authors. Xiao and colleagues [56] investigated 34 SARS-
CoV-2 confirmed cases and showed positive results for IgM and $\operatorname{IgG}$ at week 3 post symptoms onset. The decrease in IgM levels was seen at week 4; being two cases completely negative at week 5 to 6 . In accordance, Zhao and colleagues [57] investigated the antibody response to SARS-CoV-2 among 173 hospitalized patients and observed a seroconversion of $\operatorname{IgM}$ and $\operatorname{IgG}$ around day-12 and day-14, respectively. Pan and colleagues[58], showed that, after the first week of symptoms onset, only $11 \%$ of 86 cases had a detectable IgM response. The seropositive response increased between 8 and 14 days after PSO for IgM and IgG. The data report low positivity for IgG after PSO and high levels at later points (more than 15 days).

However, some works demonstrated that this scenario of preceding and declining IgM, followed by a late seroconversion of $\mathrm{IgG}$, seemed not to be generally applicable to SARS-CoV-2 infection [55]. The high discrepancy of the patterns of IgM and IgG seroconversions related to SARS-CoV-2 was reported by Qu and colleagues (2020) [59]. The group observed that the mediam time of seroconversion for IgG was 11 days and 14 days for IgM. Therefore, IgG seroconversion was three days earlier than that for IgM after the SARSCoV-2 infection. Liu and colleagues (2020) [60] evaluated 23 confirmed cases of SARS-CoV-2 infection and report seroconversion at day 7 or later after the infection, with appearance of $\operatorname{IgM}$ and IgG in parallel and only in a few cases with either isolated IgM or IgG. These results highlight the variability of serological response, as well as appearance of IgM and IgG for SARS-CoV-2 disease.

More considerably, detectable levels of total antibodies were found in the sera of patients with undetectable levels of RNA in their respiratory tract samples. This evidence highlighted the extreme importance to combine molecular and serological tests for the exact diagnosis of COVID-19 patients at different stages of the disease [57]. The work report by Pan and colleagues [58], also demonstrated that $43.6 \%$ of PCR-negative cases showing clinical symptoms for SARS-CoV-2 
found to be positive for antibodies against SARSCoV-2. The inconsistency between the PCR and antibody results might indicate a wrong time point of taking samples for the PCR test being either too late, or that sampling or other critical steps had not been efficient.

\section{Immune Response Assessment Methods}

Since the emergence of the COVID-19 pandemic, several research teams around the world have applied a huge effort to develop and improve different diagnostics methods to detect the immunological response against SARSCoV-2 infection [61]. The evaluation of humoral and cellular response is important to understand the disease epidemiology, including the asymptomatic infection rate and the protection level in a given population. This information is pivotal to the governs make decisions regarding social distance, lockdown and to improve the public hospital capacities. Moreover, the assays to measure immune response against SARSCoV-2 may help the governs to reopen borders and get employees back to work, limiting the economic damage [62]. The search of the presence of antibodies and T-cell response against SARS-CoV-2 are two diagnostic ways to measure the host response against the virus. The T-cell response against S-glycoprotein has been characterized and correlates to IgG and IgA antibodies and the production of interferons are known to control viral infection [63]. Interferons are widely used to treat viral infections such as hepatitis $\mathrm{B}$ and $\mathrm{C}$, and IFN- $\alpha$ decreases virus titer in the lungs of SARS-CoV-infected macaques [64], suggesting it may be a pharmacological treatment for COVID-19. However, measure interferon production by T-lymphocytes is a strategy to determine previous infections, host response capability to fight against the virus and also associate the host cellular response to the clinical outcome. Actually, this diagnostic is applied to Mycobacterium tuberculosis infection, known as QuantiFERON® [65]. In this case, the blood of the patient is incubated in contact to a mix of peptide antigens from M. tubesculosis. In the end, the level of IFN- $\gamma$ produced is determined by ELISA (enzyme-linked immunosorbent assay). For COVID-19, there is no approach regarding the measurement of IFN- $\gamma$ as a readout of immune response status against SARS-CoV-2.

Nowadays, the most common diagnostic methods to evaluate the immunological response against SARS-CoV-2 are based on the detection of antibodies. Tests based on the antibody detection are important to determine if people have been infected by a such pathogen. The infection stimulates the recognition of antigens by the immune system, triggering the production of specific antibodies which will be secreted by plasm cells. It is noteworthy the SARS-CoV-2 serology may be complementary to the RT-qPCR and for epidemiological studies. The serology may be used to confirm or exclude COVID-19 in such situations: 1) consecutive negative RTqPCR results associated to the presence of clinical symptoms; 2) for infectious control in hospitalized patient presenting more than twenty days of suggestive clinical symptoms; 3) COVID-19 atypical manifestations (GuillainBarré syndrome, meningo-encephalitis, cutaneous vasculitis, Kawasaki disease and diarrhea); 4) pre transplant or chemotherapy treatment [66].

Serological tests include neutralization assays, chemiluminescent immunoassay (CLIA), ELISA (Figure 3) and lateral-flow tests (Figure 4) $[67,68]$. To detect the presence of neutralizing antibodies in human plasm it is possible to apply technics such as replicative component virus or pseudotyped viral particle-based entry assays. However, the first one is timing consuming and must be used in a biosafety level 3 laboratory structure, while the second option is not trivial to be produced. CLIA, ELISA and lateral-flow tests, apply an enzyme, fluorophore or colloidal gold-tagged secondary antibody to detect the presence of antibodies in the patient serum. For these assays an important tool is the SARS- 
Figure 3. Overview of rapid diagnostic serological test.

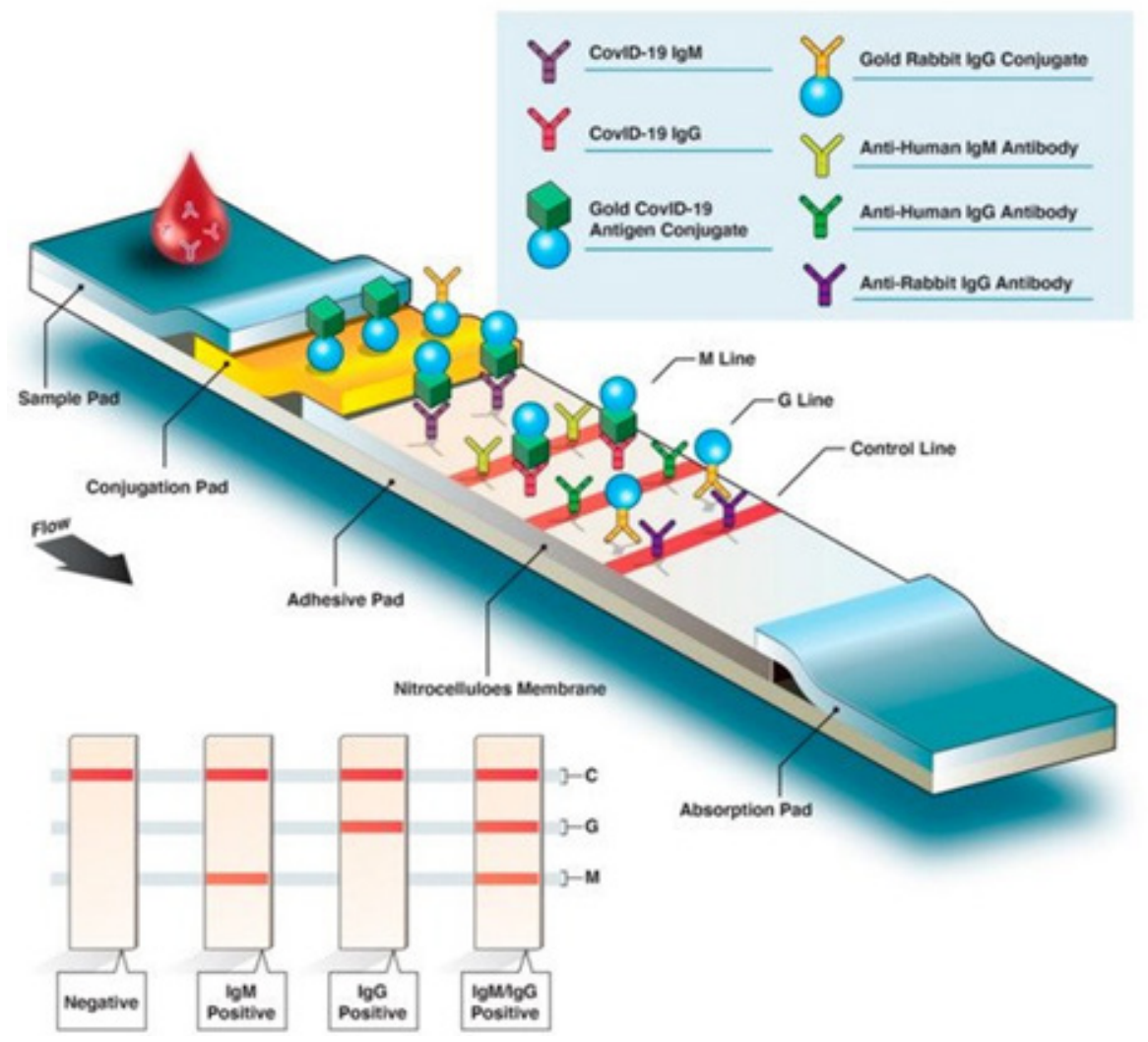

Rapid diagnostic tests (RDTs) are typically based on colorimetric lateral flow immunoassay, in which host antibodies migrate across an adhesive pad (e.g., nitrocellulose) and interact with bound virus-specific antigens and secondary antibodies (antihuman IgM/G antibodies). Conjugated SARS-CoV-2-specific antigen(s) (labeled with gold here) will bind with the corresponding host antibodies. As antibody-antigen complexes travel up the membrane, bound anti-SARS-CoV-2 IgM antibodies interact with fixed anti-IgM secondary antibodies on the M line, and anti-SARS-CoV-2 IgG antibodies interact with anti-IgG antibodies on the G line. If the blood sample does not contain SARS-CoV-2specific antibodies, the M or G lines do not appear in the final test results; only the control (C) line will be revealed.

Source/Credit: Ghaffari [67].

$\mathrm{CoV}-2$ antigens produced in laboratory. The $\mathrm{S}$ and $\mathrm{N}$ protein are usually used in these diagnostics. While the N-protein is the most abundant and immunogenic protein (then easier to detect) [69], (S) glycoprotein may elicit neutralizing antibody targeting the RBD [70]. N-protein is relatively small and highly conserved among coronavirus infecting human, allowing false positive results because of cross-reactions to other coronaviruses. On the other hand, S-glycoprotein is less conserved and may stimulate the production of more specific antibodies, as a consequence of glycosylated sites and its complex trimeric conformation. A heterogeneity in antibody development against these antigens have been observed. The anti-N antibodies were showed to appear earlier than anti-S during the infection, and the detection of both antibodies may be complementary during the serological screenings to improve the assay sensibility [71].

One of the first studies which evaluated these commercial serological assays tested the performance of 10 ELISAS, 4 CLIA and 3 lateral-flow tests, to measure the presence of $\operatorname{IgM}, \operatorname{IgG}$ and $\operatorname{IgA}$ in 582 sera (178 and 404 positive and negative, respectively). As expected, the antibodies titer increased overtime post-symptoms and was detected by most of the 
Figure 4. Schematic representation of an ELISA or CLIA assay.

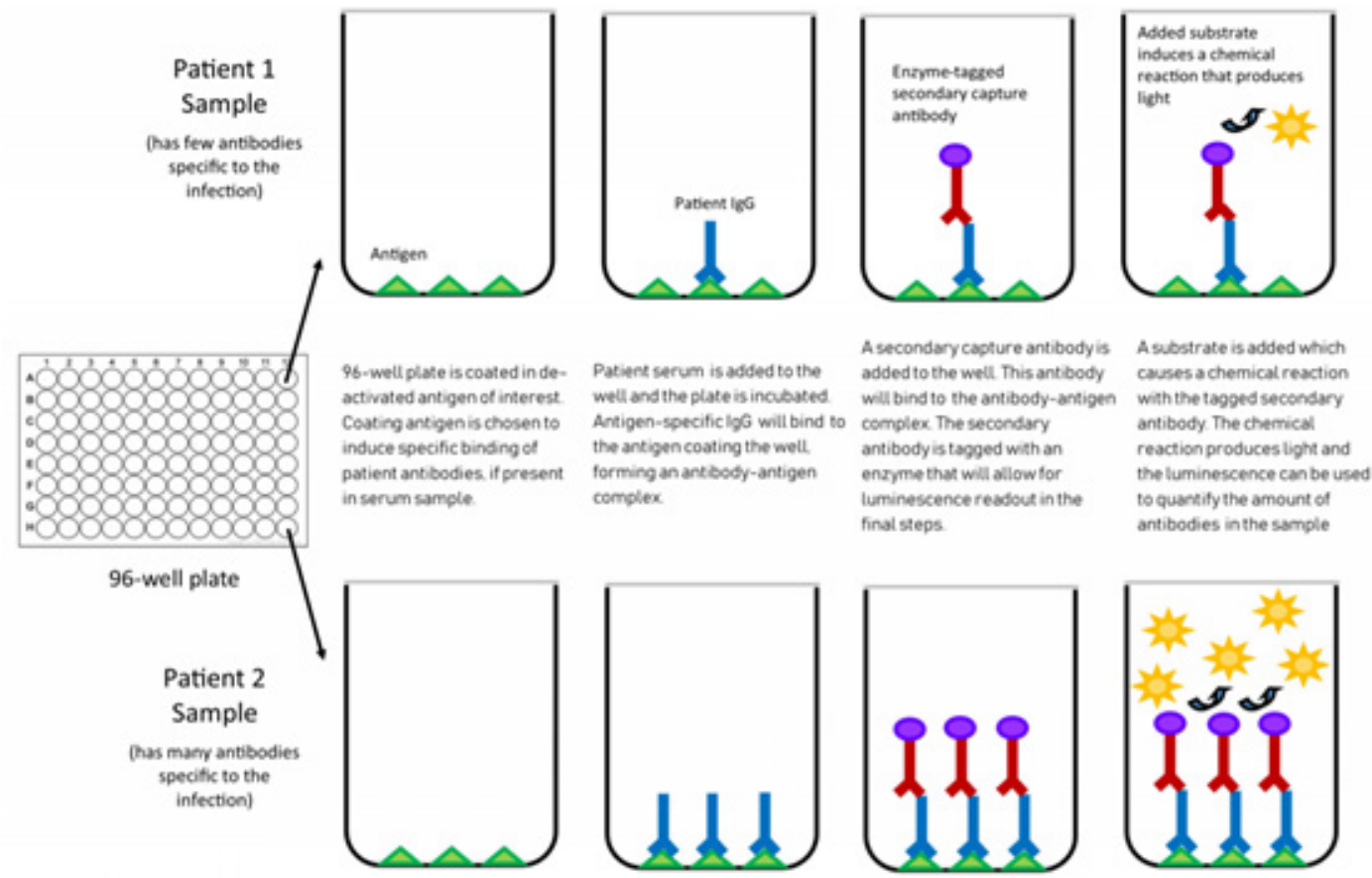

Both serological tests are performed in antigen coated plates where patient serum is added. The human antibodies directed against SARSCoV-2 antigen is detected by a seconday labeled antibodies, which could be conjugated to a horesedharsh peroxidase (ELISA) or a fluoroforo (CLIA). The signal intensity will be proportional to the antibody titer in the sample.

Credit/Source: Serology testing for COVID-19. Center for Health Security. Johns Hopkins University 2020 [68].

brands tested. Regardless the serological method applied, IgG antibodies increased after 15 days post-symptoms and generate a sensibility of $90 \%$. Cross reaction was not observed in this study using samples from another human seasonal coronavirus and others virus infection. These same authors showed that lateral flow testes could detect $90 \%$ of $\operatorname{IgM}$ from infected patients and in all $\operatorname{IgM}$ positive assays, $\operatorname{IgG}$ was also present [66]. It suggests that the detection of IgM alone may be useless for the recent diagnostic of COVID-19, as determined by a longitudinal profile of $\operatorname{IgG}, \operatorname{IgM}$ and $\operatorname{IgA}$ antibodies [72,73].

A meta-analysis performed by Bastos and colleagues [74], found that the methodology applied to conduct the accuracy of serological tests for COVID-19 are associated to high risk of patient selection bias as well as the risk regarding to the interpretation of the results. The sensitivity was higher after three weeks of symptoms onset for CLIA, ELISA and lateral flow method, in accordance to the study abovementioned. In all analysis, the sensitivity of lateral-flow based tests was the lowest detected [74]. The lateral-flow methodology is easier to perform and faster than CLIA and ELISA, then it has been commonly used around the world and is a potential pointof-care method. However, the performance of this method must be evaluated in depth. Another metanalysis searched for the accuracy of rapid tests registered in Brazil during the pandemic. This study showed this kind of test may be associated to false negative results [75].

In summary, the evidence for high performance of serological tests are weak, mainly if the methods are applied as point of care diagnosis. Then, caution is necessary when use serological tests available for clinical decision and epidemiological surveillance. Moreover, the researchers must consider the antigen used for the development of these tests, since evidences suggest the response against the $\mathrm{N}$-protein or $\mathrm{S}$-glycoprotein influences the prognosis of the disease [76]. 


\section{Concluding Remarks}

In view of the rapid spread of SARS-CoV-2 and the unknown nature of the virus, both basic science and clinical science had to intensify scientific production regarding SARS-CoV-2 in a few months in order to generate useful information for the viral infection control. Previous knowledge about other coronaviruses, such as SARS-CoV-1 and MERS-CoV, were the pillars for understanding the immune response of SARS-CoV-2. Until now, we know that the anti-SARS-CoV-2 immune response in the host involves mechanisms related to innate immunity, activation of CD4+ and CD8+ T cells and production of antibodies ( $\operatorname{IgA}, \operatorname{IgG}$ and IgM) against the virus. Despite the similarities with other coronoviruses, the immune response against SARS-CoV-2 has been showing some distinct characteristics that need to be better clarified, such as, for example, the kinetics of antibody production. In this fashion, we can conclude that additional studies need to be done to a better description of the immune response against SARS-CoV-2.

\section{References}

1. Lu H, Straton CW, Tang YW. Outbreak of pneumonia of unknown etiology in wuhan China: the mystery and the miracle. J Med Virol. 2020;92(4):401-402.

2. World Health Organization. WHO Director- General's opening remarks at the media briefing on COVID-19 - 11 March 2020. WHO https://www.who.int/dg/ speeches/ detail/who- director- general- s- openingremarks- at- themedia- briefing- on- COVID-19---11- march-2020, 2020a.

3. Munster VJ, Koopmans M, Van Doremalen N, Van Riel $\mathrm{D}$, De Wit E. A novel coronavirus emerging in China - key questions for impact assessment. N Engl J Med. 2020;382(8):692-694.

4. World Heath Organization. WHO coronavirus disease (COVID-19) dashboard - 4 November 2020. WHO covid19. who.int, 2020b.

5. De Wit E, Van Doremanlen N, Falzarano D, Munster VJ. SARS and MERS: recent insights into emerging coronaviruses. Nat Rev Microbiol. 2016;14(8): 523-534.

6. Chafekar A, Fielding BC. MERS-CoV: Understanding the latest human coronavirus threat. Viruses. 2018;10(2):93.

7. Sariol A, Perlman S. Lessons for COVID-19 immunity from other coronavirus infections. Immunity. 2020;53(2):248263.
8. Naqvi AAT, Fatima K, Mohammad T, Fatima U, Singh IK, Singh A, et al. Insights into SARS-CoV-2 genome, structure, evolution, pathogenesis and therapies: Structural genomics approach. Biochimica et Biophysica Acta (BBA)-Molecular Basis of Disease. 2020;1866(1):165878.

9. Kang S, Yang M, Hong Z, Zhang L, Huang Z, Chen X, et al. Crystal structure of SARS-CoV-2 nucleocapsid protein RNA binding domain reveals potential unique drug targeting sites. Acta Pharmaceutica Sinica B. 2020;10(7):1228-1238.

10. Rabaan AA, Al-Ahmed SH, Haque S, et al. SARS-CoV-2, SARS-CoV, and MERS-COV: A comparative overview. Infez Med. 2020;28(2):174-184.

11. Walls AC, Park YJ, Tortorici MA, Wall A, McGuire AT, Veesler D. Structure, Function, and Antigenicity of the SARSCoV-2 Spike Glycoprotein. Cell. 2020;181(2):281-292.e6.

12. Astuti I, Ysrafil. Severe Acute Respiratory Syndrome Coronavirus 2 (SARS-CoV-2): An overview of viral structure and host response. Diabetes Metab Syndr. 2020;14(4):407-412.

13. Coutard B, Valle C, de Lamballerie X, Canard B, Seidah NG, Decroly E. The spike glycoprotein of the new coronavirus 2019-nCoV contains a furin-like cleavage site absent in CoV of the same clade. Antiviral Res. 2020;176:104742.

14. Wang Q, Zhang Y, Wu L, et al. Structural and Functional Basis of SARS-CoV-2 Entry by Using Human ACE2. Cell. 2020;181(4):894-904.e9.

15. Schoeman D, Fielding BC. Coronavirus envelope protein: current knowledge. Virol J. 2019;16(1):69.

15a. Naqvi AAT, Fatima K, Mohammad T, Fatima U, Singh IK, Singh A, et al. Insights into SARS-CoV-2 genome, structure, evolution, pathogenesis and therapies: Structural genomics approach. Biochimica et Biophysica Acta (BBA)-Molecular Basis of Disease. 2020;1866(1): 165878.

16. Alberts B, Johnson A, Lewis J, et al. Molecular Biology of the Cell. 4th ed. New York: Garland Science; 2002. Available from: https://www.ncbi.nlm.nih.gov/books/NBK26846 /\# ncbi_dlg_citbx_NBK26846 [Accessed 05th Sep 2020].

17. Vabret N, Britton G J, Gruber C, Hegde S, Kim J, Kuksin M, et al. Immunology of COVID-19: current state of the science. Immunity. 2020;52(6):910-941.

18. Zhou Z, Ren L, Zhang L, Zhong J, Xiao Y, Jia Z, et al. Heightened innate immune responses in the respiratory tract of COVID-19 patients. Cell Host \& Microbe. 2020;27(6):883890.

19. Frederiksen LSF, Zhang Y, Foged C, Thakur A. The long road toward COVID-19 herd immunity: vaccine platform Technologies and mass immunization strategies. Frontiers in immunology. 2020;11:1817.

20. Ivashkiv LB, Donlin LT. Regulation of type I interferon responses. Nature reviews Immunology. 2014;14(1):36-49.

21. Trouillet-Assant S, Viel S, Gaymard A, Pons S, Richard JC, Perret M, et al. Type I IFN immunoprofiling in COVID-19 patients. Journal of Allergy and Clinical Immunology. 2020;146(1):206-208.

22. Acharya D, Liu G, Gack MU. Dysregulation of type I interferon responses in COVID-19. Nature Reviews Immunology. 2020;20:397-398.

23. Schulte-Schrepping J, Reusch N, Paclik D, Baßler K, Schlickeiser S, Zhang B, et al. Severe COVID-19 is marked by a dysregulated myeloid cell compartment. Cell. 2020;182(6):1419-1440. 
24. Didangelos A. COVID-19 Hyperinflammation: What about Neutrophils?. MSphere. 2020;5(3):1-5.

25. Zuo Y, Yalavarthi S, Shi H,Gockman K, Zuo M, Madison JA, et al. Neutrophil extracellular traps in COVID-19. JCI Insight. 2020;5(11):e138999.

26. Maucourant C, Filipovic I, Ponzetta A, Aleman S, Cornillet M, Hertwig L, et al. Natural killer cell immunotypes related to COVID-19 disease severity. Sci Immunol. 2020;5(50):eabd6832.

27. Maucourant C, Filipovic I, Ponzetta A, Aleman S, Cornillet M, Hertwig L, et al. Natural killer cell activation related to clinical outcome of COVID-19. medRxiv. [Preprint] 2020. Available from: doi.org/10.1101/2020.07.07.20148478

28. Tezer H, Demirdag TB. Novel coronavirus disease (COVID-19) in children. Turk J Med Sci. 2020;50(3):592-603.

29. Kloc M, Ghobrial RM, Kuchar E, Lewicki S, et al. Development of child immunity in the context of COVID-19 pandemic. Clin Immunol. 2020;217: 108510.

30. Fischer A. Resistance of children to COVID-19. How? Mucosal Immunol. 2020; 13(4):563-565.

31. Molloy EJ, Bearer CF. COVID-19 in children and altered inflammatory responses. Pediatr Res. 2020;88(3):340-341.

32. Shaw AC, Goldstein DR, Montgomery RR. Age-dependent dysregulation of innate immunity. Nature Reviews Immunology. 2013;13(12):875-887.

33. Rao V, Arakeri G, Subash A, Rao J, Jadhav S, Sayeed MS et al. COVID-19: loss of bridging between innate and adaptive immunity? Med Hypotheses. 2020; 144:109861.

34. Azkur AK, Akdis M, Azkur D, et al. Immune response to SARS-CoV-2 and mechanisms os immunopathological changes in COVID-19. Allergy. 2020;75(7):1564-1581.

35. Cecere TE, Todd SM, Leroith T. Regulatory $\mathrm{T}$ cells in arterivirus and coronavirus infections: do they protect against disease or enhance it? Viruses. 2012;4(5):833-846.

36. Li G, Fan Y, Lai Y, et al. Coronavirus infections and immune responses. J Med Virol. 2020, 92: 424-432.

37. Zhou F, Yu T, Du R, Fan G, Liu Y, Liu Z, et al. Clinical course and risk factors for mortality of adult inpatients with COVID-19 in Wuhan, China: a retrospective cohort study. Lancet. 2020;395(10229):1054-1062.

38. Qin C, Zhou L, Hu Z, Zhang S, Yang S, Tao Y, et al. Dysregulation of immune response in patients with coronavirus 2019 (COVID-19) in Wuhan, China. Clin Infect Dis. 2020;71(15):762-768.

39. Maloir Q, Ghysen K, von Frenckell C, Louis R, Guiot J. Acute respiratory distress revealing antisynthetase syndrome. Rev Med Liege. 2018;73(7-8):370-375.

40. García LF. Immune response, inflammation, and the clinical spectrum of COVID-19. Front Immunol. 2020;11:1441.

41. Sakaguchi S, Miyara M, Costantino CM, Hafler DA. FOXP3+ regulatory $\mathrm{T}$ cells in the human immune system. Nat Rev Immunol. 2010;10(7):490-500.

42. Clay C, Donart N, Fomukong N, Knight BJ, Lei W, Price L, et al. Primary severe acute respiratory syndrome coronavirus infection limits replication but not lung inflammation upon homologous rechallenge. J Virol. 2012;86:4234-44.

43. Oh HLJ, Chia A, Chang CXL, Leong HN, Ling KL, Grotenbreg GM, et al. Engineering T cells specific for a dominant severe acute respiratory syndrome coronavirus CD8 T cell epitope. J Virol. 2011;85(20):10464-10471.
44. Ng OW, Chia A, Tan AT, et al. Memory $\mathrm{T}$ cell responses targeting the SARS coronavirus persist up to 11 years postinfection. Vaccine. 2016;34(17):2008-2014.

45. Ahmed SF, Quadeer AA, McKay MR. Preliminary Identification of Potential Vaccine Targets for the COVID-19 Coronavirus (SARS-CoV-2) Based on SARS-CoV Immunological Studies. Viruses. 2020;12(3):254.

46. Grifoni A, Sidney J, Zhang Y, Scheuermann RH, Peters B, Sette A. A Sequence Homology and Bioinformatic Approach Can Predict Candidate Targets for Immune Responses to SARS-CoV-2. Cell Host Microbe. 2020;27(4):671-680.

47. Ju B, Zhang Q, Ge X, Wang R, Sun J, Ge X, et al. Human neutralizing antibodies elicited by SARS-CoV-2 infection. Nature. 2020;584:115-119.

48. Paces J, Strizova Z, Smrz D, Cerny J. COVID-19 and the immune system. Physiol Res. 2020;69(3):379-388.

49. Rokni M, Ghasemi V, Tavakoli Z. Immune responses and pathogenesis of SARS-CoV-2 during an outbreak in Iran: Comparison with SARS and MERS. Rev Med Virol. 2020;30(3):e2107.

50. Mo H, Xu J, Ren X, Zeng G, Tan Y, Chen R, et al. Evaluation by indirect immunofluorescent assay and enzyme linked immunosorbent assay of the dynamic changes of serum antibody responses against severe acute respiratory syndrome coronavirus. Chin Med J. (2005) 118:446-50.

51. Chen S, Lu D, Zhang M, Che J, Yin Z, Zhang S, et al. Doubleantigen sandwich ELISA for detection of antibodies to SARSassociated coronavirus in human serum. Eur J Clin Microbiol Infect Dis. 2005;24:549-553.

52. Cao X. COVID-19: immunopathology and its implications for therapy. Nat Rev Immunol. 2020;20:269-70.

53. Huang C, Wang Y, Li X, Ren L, Zhao J, Hu Y, et al. Clinical features of patients infected with 2019 novel coronavirus in Wuhan, China. Lancet. 2020;395(10223):497-506.

54. Guo L, Ren L, Yang S, Xiao M, Chang D, Yang F, et al. Profiling early humoral response to diagnose novel coronavirus disease (COVID-19). Clin. Infect. Dis. 2020;71(15):778-785.

55. Bauer $\mathrm{G}$. The variability of the serological response to SARS corona virus-2: Potential resolution of ambiguity through determination of avidity (functional affinity). J Med Virol. 2020;10: 002/jmv.26262.

56. Xiao AT, Gao C, Zhang S. Profile of specific antibodies to SARS-CoV-2: the first report. J Infect. 2020;81(1):147-178.

57. Zhao J, Yuan Q, Wang H, Liu W, Liao X, Su Y, et al. Antibody responses to SARS-CoV-2 in patients of novel coronavirus disease 2019. Clin Infect Dis. 2020: ciaa344.

58. Pan Y, Li X, Yang G, Fan J, Tang Y, Zhao J, et al. Serological immunochromatographic approach in diagnosis with SARS-CoV-2 infected COVID-19 patients. J Infection. 2020;81(1):E28-E32.

59. Qu J, Wu C, Li X, Zhang G, Jiang Z, Li X, et al. Profile of IgG and $\mathrm{IgM}$ antibodies against severe acute respiratory syndrome coronavirus 2 (SARS-CoV-2). Clin Infect Dis. 2020:ciaa489.

60. Liu L, Liu W, Wang X, Zheng S. A preliminary study on serological assay for severe acute respiratory syndrome coronavirus 2 (SARS-CoV-2) in 238 admitted hospital patients. Microb Infect. 2020;22(4-5):206-211.

61. SARS-CoV-2 diagnostic pipeline. Available in: https://www. finddx.org/COVID-19/pipeline. Accessed in: September 20, 2020. 
62. Petherick A. Developing antibody tests for SARS-CoV-2. The Lancet. 2020;395(10230):1101-1102.

63. Grifoni A, Weiskopf D, Ramirez SI, Mateus J, Dan JM, Moderbacher CR, et al. Targets of $\mathrm{T}$ Cell Responses to SARS-CoV-2 Coronavirus in Humans with COVID-19 Disease and Unexposed Individuals. Cell. 2020;181(7):1489-1501.

64. Haagmans BL, Kuiken T, Martina BE, Fouchier RAM, Rimmelzwaan GF, Amerongen GV, et al. Pegylated interferon- $\alpha$ protects type 1 pneumocytes against SARS coronavirus infection in macaques. Nat Med. 2004;10(3):290-293.

65. Nemes E, Rozot V, Geldenhuys H, Bilek N, Mabwe S, Abrahams D, et al. Optimization and Interpretation of Serial QuantiFERON Testing to Measure Acquisition of Mycobacterium tuberculosis Infection. Am J Respir Crit Care Med. 2017;196(5):638-648.

66. Coste AT, Jaton K, Papadimitriou-Olivgeris M, Greub G, Croxatto A. Comparison of SARS-CoV-2 serological tests with different antigen targets medRxiv. 2020.

67. Ghaffari A, Meurant R, Ardakani A. COVID-19 Serological Tests: How Well Do They Actually Perform? Diagnostics. 2020;10(7):453.

68. Serology testing for COVID-19. Center for Health Security. Johns Hopikins University. 2020.

69. Zhao P, Cao J, Zhao L-J, Qin Z-L, Ke J-S, Pan W, et al. Immune responses against SARS-coronavirus nucleocapsid protein induced by DNA vaccine. Virology. 2005;331(1):128135.
70. Berry JD, Hay K, Rini JM, Yu M, Wang L, Plummer FA, et al. Neutralizing epitopes of the SARS-CoV S-protein cluster independent of repertoire, antigen structure or mAb technology. MAbs. 2010;2(1):53-66.

71. Infantino M, Damiani A, Gobbi FL, Grossi V, Lari B, Macchia $\mathrm{D}$, et al. Serological Assays for SARS-CoV-2 Infectious Disease: Benefits, Limitations and Perspectives. Isr Med Assoc J. 2020;22(4):203-210.

72. Woo PCY, Lau SKP, Wong BHL, Chu CM, Tsoi HW, Huang $\mathrm{Y}$, et al. Longitudinal profile of immunoglobulin $\mathrm{G}$ ( $\mathrm{IgG})$, $\operatorname{IgM}$, and $\operatorname{IgA}$ antibodies against the severe acute respiratory syndrome (SARS) coronavirus nucleocapsid protein in patients with pneumonia due to the SARS coronavirus. Clin Diagn Lab Immunol. 2004;11(4):665-668.

73. Bauer $\mathrm{G}$. The variability of the serological response to SARScorona virus-2: Potential resolution of ambiguity through determination of avidity (functional affinity). J Med Virol. 2020;1-12.

74. Bastos ML, Tavaziva G, Abidi SK, Campbell JR, Haraoui LP, Johnston JC, et al. Diagnostic accuracy of serological tests for COVID-19: systematic review and meta-analysis. BMJ. 2020;370:m2516.

75. Castro R, Luz PM, Wakimoto MD, Veloso VG, Grinsztejn B, Perazzo H. COVID-19: a meta-analysis of diagnostic test accuracy of commercial assays registered in Brazil. Braz J Infect Dis. 2020;24(2):180-187.

76. Atyeo C, Fischinger S, Zohar T, Slein MD, Burke J, Loos C, et al. Distinct Early Serological Signatures Track with SARSCoV-2 Survival. Immunity. 2020;53:1-9. 